\title{
Determinants of Prison Experience among Homicide and Non-Homicide Offenders in Nigeria
}

\author{
Article by Aishatu Yusha'u Armiya'u', Adegboyega Ogunwale ${ }^{2}$, Lubuola Issa Bamidele ${ }^{3}$, \\ Opeyemi Faith Akinyemi ${ }^{1}$ \\ ${ }^{1}$ Forensic Unit, Department of Psychiatry, Jos University Teaching Hospital Jos. Plateau \\ state Nigeria \\ ${ }^{2}$ Forensic Unit, Department of Clinical Services, Neuropsychiatric Hospital, Aro, Abeokuta, \\ Ogun State, Nigeria \\ ${ }^{3}$ Katsina psychiatric hospital, Katsina state Nigeria \\ E-mail:aarmiyau@gmail.com ${ }^{1}$
}

\begin{abstract}
Background: Large numbers of stimuli are contained within the prison environment which can impact both the behaviour and attitudes of inmates within it. This inmate-environment interaction has implication for the safety and overall well-being of inmates.

Objectives: This study aimed to compare the differences between homicide and non-homicide offenders in relation to effects of prison environmental factors. The relationship between these factors and sociodemographic factors was also explored and compared between both groups of offenders.

Methods: A case-control study design was employed with 102 homicide and an equal number of nonhomicide offenders. Each participant was interviewed using a questionnaire for ascertaining sociodemographic characteristics as well as the Prison Environment Inventory for inmates concerns within the prison.

Results: A significant association was found in all prison environment subscales between offender groups except safety $(p=0.060)$ and privacy $(p=0.084)$ with homicide offenders having better total overall score in the prison environment. A younger age and higher educational attainment were associated with better prison experience.

Conclusion: The study found an overall better adjustment in homicide offenders compared to their non-homicide counterparts. However, prison administrators have a role in improving specific aspects of prisoner experience for both homicide and non-homicide offenders during incarceration.
\end{abstract}

Keywords: Prison, Environment, Homicide, Nigeria, Maximum security.

\section{Introduction}

Prison inmates experience severe stressors in their physical and social environments that may be inimical to their well-being [1]. The distress encountered by inmates is likely to increase the need for supportive social relationships. In the same manner, confinement from public space isolates inmates from social networks formed in the mainstream society and further exposes them to new social networks inside the prison institution [2]. In addition, prison design limits freedom of movement and choice, thus placing inmates in subordinate and dependent roles which can impact on well-being [3].

To make the matter worse, inmates face an environment laden with violence, overcrowding, segregation (Homicide and Non homicide offenders), the compulsive need to comply with the rigid authoritarian organization and water-tight ritualized schedule [4].

The prison environment can have a profound negative impact on physical, mental and emotional wellbeing of inmates [5]. For negative effects to come to fruition there needs to be catalysts within the prison environment that enables them. These catalysts constitute a wide number of factors that may include, but not limited to, theft, overcrowding, riots and violence, poor structured prison operation, and assaults [5]. 
DOI: $10.21522 / \mathrm{TIJMD}$.2013.07.01.Art007

ISSN: $2520-3118$

Looking specifically to the negative effects of the prison environment, a study found three important correlates: spatial intrusion, monotony, and external control [5]. Spatial intrusion is concerned with problems arising from invasion of space, or threats to one's personal space. Monotony concerns with boredom and the day-to-day inactivity inmates' experience. External control relates to the dictates by the administration such as rules and regulations, which can be problematic for inmates if a rule limits their privacy or freedom. These three factors serve as catalysts for increasing the propensity of aggression in prison [6]. Others causes include shortage of staff and inmate population (i.e. administration and overcrowding).

The implications of this unique set of circumstances in a supposed correctional centre on general wellbeing have not been widely studied. Furthermore, studies of the influence on different category of offenders are virtually non-existent in the low- and middle-income countries. The available studies assessed the impact of prison environments on mental health with little or no consideration for the general well-being of the inmates [7-9].

The well-being of inmates in terms of emotional need, safety, life cycle roles, friendships are similar regardless of where they may find themselves [10-12]. In prison environments, many of these needs are left inadequately fulfilled as the inmates find themselves in a completely different environment with its peculiarities.

This current study aimed to examine the experience of the prison environment especially in low income countries like Nigeria by homicide and non-homicide incarcerated offender and the relationship that this experience demonstrates with their sociodemographic variables. This investigation has significant implications for the overall well-being of prison inmates and should provide policy makers within the prison administration with the necessary targets for appropriate socio-physical interventions.

\section{Methodology}

\section{Study design and location}

A case-control study was conducted among homicide and non-homicide offenders who were sentenced at the Jos maximum security prison, in Plateau state Nigeria. It involved 102 offenders per group so as to identify and compare factors that may differentiate between these two groups of offenders.

\section{Sample size calculation: for case control studies}

Sample size for the study was calculated using the case-control studies formula used by Cai, and Zeng in 2004 [13]. Sample size calculated was 101.6 which was approximated to 102 per studied group. The Homicide offenders were the cases while non-homicide counterparts were the controls in the study.

\section{Instruments}

\section{Sociodemographic characteristic questionnaire}

The researchers designed a questionnaire which was used to collect important socio-demographic data such as age, highest level of education, marital status, and employment status, among others.

\section{Prison environment inventory (PEI)}

This is a 48-item scale scored in terms of seven factors: program structure, emotional feedback, social climate, staff support, activity planning, safety and privacy [3]. Even though these dimensions have some face validity, the reliability and validity of instrument are yet to be available.

Using structural equation modelling (SEM), confirmatory factors analysis combining medium and maximum prison inmate sample showed that dimension of activity, emotional feedback, freedom, privacy, safety, social, structure, support [3] structural scale [14]. The SEM result reveals the dimensions measured intended areas of inmate concern, and analysis replicated study [3], which found PEI scale a reliable measure of inmate concerns [14]. 


\section{Analysis}

The Statistical Package for Social Sciences (SPSS) version 20 was used for data analysis. Sociodemographic and offense-related variables were summarized using descriptive statistics such as percentages and frequency counts.

The Student's t-test was used to analyze differences between homicide and non-homicide offenders in terms of the prison environment. Two-way analysis of variance (two-way ANOVA) was used to examine the interactions between offender status and socio-demographic characteristics as they relate to the effect of prison environment. A p value of less than 0.05 was regarded as statistically significant.

\section{Ethical consideration}

The Institutional Health Research Ethics Committee of Jos University Teaching Hospital approved the research protocol for the study. Permission to carry out the study was gotten from the Nigeria Prison Service by the Researchers. Following a clear explanation of the research to participants, a consent form is either signed or thumb printed without coercion by each participant. A serial number is given to each participant to maintain privacy.

\section{Results}

Majority of the homicide offenders $(61.8 \%)$ as well as the non-homicide offenders $(46.1 \%)$ were aged between $26-40$ years. While majority of the non-homicide offenders $(58.8 \%)$ were never married, the largest proportion of the homicide offenders were married (54.9\%). In terms of education, majority of the respondents in the homicide $(44.1 \%)$ and non-homicide $(55.9 \%)$ groups had above primary education. The larger proportion of the homicide offenders (71.6\%) were employed while majority of the nonhomicide offenders $(58.8 \%)$ were unemployed (Table 1$)$.

Table 1. Sociodemographic characteristics of offenders

\begin{tabular}{|c|c|c|c|}
\hline \multirow{2}{*}{$\begin{array}{l}\text { Demographic } \\
\text { characteristics }\end{array}$} & \multicolumn{3}{|l|}{ Offenders } \\
\hline & $\begin{array}{l}\text { Homicide } \\
\mathrm{n}(\%)\end{array}$ & $\begin{array}{l}\text { Non-homicide } \\
\mathrm{n}(\%)\end{array}$ & Total $\mathrm{n}(\%)$ \\
\hline \multicolumn{4}{|l|}{ Age group } \\
\hline$\leq 25$ & $7(6.9)$ & $44(43.1)$ & $51(25.0)$ \\
\hline $26-40$ & $63(61.8)$ & $47(46.1)$ & $110(53.9)$ \\
\hline$>40$ & $32(31.4)$ & $11(10.8)$ & $43(21.1)$ \\
\hline \multicolumn{4}{|l|}{ Religion } \\
\hline Islam & $46(45.1)$ & $17(16.7)$ & $63(30.9)$ \\
\hline Christianity & $56(54.9)$ & $85(83.3)$ & $141(69.1)$ \\
\hline \multicolumn{4}{|l|}{ Marital status } \\
\hline Never married & $37(36.3)$ & $60(58.8)$ & $97(47.5)$ \\
\hline Married & $56(54.9)$ & $33(32.4)$ & $89(43.6)$ \\
\hline Others & $9(8.8)$ & $9(8.8)$ & $18(8.8)$ \\
\hline \multicolumn{4}{|c|}{ Educational level } \\
\hline Informal & $24(23.5)$ & $13(12.7)$ & $37(18.1)$ \\
\hline Primary & $33(32.4)$ & $32(31.4)$ & $65(31.9)$ \\
\hline Above primary & $45(44.1)$ & $57(55.9)$ & $102(50.0)$ \\
\hline \multicolumn{4}{|c|}{ Employment status } \\
\hline Unemployed & $29(28.4)$ & $60(58.8)$ & $89(43.6)$ \\
\hline Employed & $73(71.6)$ & $42(41.2)$ & $115(56.4)$ \\
\hline
\end{tabular}


DOI: $10.21522 / \mathrm{TIJMD} .2013 .07 .01 . A r t 007$

ISSN: $2520-3118$

Significant association was found between offender status and all prison environment subscales apart from safety $(\mathrm{p}=0.060)$ and privacy $(\mathrm{p}=0.084)$ with homicide offenders having better sub-scale and total overall score in most cases (Table 2).

Table 2. Comparison of prison environment mean scores between offender groups

\begin{tabular}{|l|l|l|l|l|}
\hline $\begin{array}{l}\text { Prison } \\
\text { environment }\end{array}$ & \multicolumn{2}{l|}{ Category of offenders } & t-test & $\mathrm{P}$ \\
\hline (Subscale/Total) & Homicide & $\begin{array}{l}\text { Non- } \\
\text { homicide }\end{array}$ & & \\
\hline Structure & $0.77 \pm 0.23$ & $0.67 \pm 0.26$ & 2.833 & 0.005 \\
\hline $\begin{array}{l}\text { Emotional } \\
\text { feedback }\end{array}$ & $0.83 \pm 0.24$ & $0.66 \pm 0.26$ & 4.815 & 0.001 \\
\hline Activity & $0.68 \pm 0.19$ & $0.61 \pm 0.26$ & 2.122 & 0.035 \\
\hline Safety & $0.49 \pm 0.27$ & $0.55 \pm 0.24$ & 1.890 & 0.060 \\
\hline Social & $0.78 \pm 0.25$ & $0.62 \pm 0.29$ & 4.238 & 0.001 \\
\hline Support & $0.83 \pm 0.25$ & $0.61 \pm 0.28$ & 5.851 & 0.001 \\
\hline Privacy & $0.69 \pm 0.28$ & $0.62 \pm 0.26$ & 1.737 & 0.084 \\
\hline Freedom & $0.45 \pm 0.25$ & $0.55 \pm 0.233$ & 2.845 & 0.005 \\
\hline Total & $0.69 \pm 0.18$ & $0.61 \pm 0.20$ & 2.959 & 0.003 \\
\hline
\end{tabular}

As shown in Table 3, an association was found between total prison environment mean scores and age of participants $(\mathrm{F}=12.643, \mathrm{p}=0.001)$ with those who were $\leq 25$ years having significantly lower scores than those who were older (refer to table on pairwise as supplementary table). However, there was an interaction between age group and offender status $(\mathrm{p}=0.038)$. The variation in association showed that while the total prison environments mean score was lowest among $\leq 25$-year olds in the non-homicide category, the score was highest among those $\leq 25$ in the homicide offender group. An association was also found between total prison environment mean scores and educational status; those who had above primary education had significantly higher mean scores (refer to table on pairwise as supplementary table). However, there was no significant interaction between offender status and educational level $(\mathrm{p}=$ $0.103)$ suggesting no variation to this association between homicide and non-homicide offenders. There was no association between total prison environment mean score and either employment or marital status.

Table 3. Effect of socio-demographic factors and offender status on total Prison environment means scores between offender groups

\begin{tabular}{|c|c|c|c|c|c|c|c|c|}
\hline \multirow[t]{2}{*}{$\begin{array}{l}\text { Socio- } \\
\text { demographic }\end{array}$} & \multicolumn{2}{|c|}{$\begin{array}{l}\text { Total prison environment } \\
\text { mean scores }\end{array}$} & \multirow[t]{2}{*}{$\mathrm{F}_{\text {Homi }}$} & \multirow[t]{2}{*}{$\mathrm{P}$} & \multirow[t]{2}{*}{$\mathrm{F}_{\text {Socio }}$} & \multirow[t]{2}{*}{$\mathrm{P}$} & \multirow[t]{2}{*}{$\mathrm{F}_{\text {Inter }}$} & \multirow[t]{2}{*}{$\mathrm{P}$} \\
\hline & Homicide & Non homicide & & & & & & \\
\hline \multicolumn{9}{|l|}{ Age group } \\
\hline$\leq 25$ & $0.77 \pm 0.11$ & $0.55 \pm 0.15$ & 12.643 & $0.001 *$ & 0.378 & 0.686 & 3.315 & $0.038^{*}$ \\
\hline $26-40$ & $0.69 \pm 0.20$ & $0.66 \pm 0.20$ & & & & & & \\
\hline$>40$ & $0.71 \pm 0.11$ & $0.58 \pm 0.22$ & & & & & & \\
\hline \multicolumn{9}{|c|}{ Educational level } \\
\hline Informal & $0.71 \pm 0.15$ & $0.51 \pm 0.13$ & 19.894 & $0.001 *$ & 3.471 & $0.033 *$ & 2.295 & 0.103 \\
\hline Primary & $0.68 \pm 0.22$ & $0.55 \pm 0.18$ & & & & & & \\
\hline Above primary & $0.71 \pm 0.16$ & $0.65 \pm 0.20$ & & & & & & \\
\hline \multicolumn{9}{|c|}{ Employment status } \\
\hline Unemployed & $0.70 \pm 0.12$ & $0.62 \pm 0.20$ & 12.719 & $0.001 *$ & 0.322 & 0.571 & 0.488 & 0.486 \\
\hline Employed & $0.70 \pm 0.19$ & $0.58 \pm 0.18$ & & & & & & \\
\hline
\end{tabular}




\begin{tabular}{|l|l|l|l|l|l|l|l|l|}
\hline Never married & $0.71 \pm 0.14$ & $0.57 \pm 0.17$ & 1.405 & 0.237 & 1.418 & 0.245 & 2.600 & 0.077 \\
\hline Married & $0.70 \pm 0.19$ & $0.64 \pm 0.22$ & & & & & & \\
\hline Others** & $0.68 \pm 0.23$ & $0.75 \pm 0.20$ & & & & & & \\
\hline
\end{tabular}

$F_{\text {Hom. }}$ - main effect of homicide status $F_{\text {Socio- }}$ main effect of socio-demographic.

$F_{\text {Inter }}-$ effect of interaction term. *significant level, **separated, widowed or divorced

\section{Discussion}

The study found that homicide participants gave a better overall rating for the prison environment compared to non-homicide participants. However, going by the subscales homicide participants rated safety and freedom in the prison as lower than the non-homicide group. But all other subscales were rated higher by homicide participants which include: structure, emotional feedback, support, social, activity and privacy. The homicide offenders stay in a different place within the study site (maximum security prison), are fewer in their cells, get the best food, involved in activities within their area of the prison and relate to each other well and the prison staff. This is likely to be the reason why they rated the prison environment better. For the lower rating on safety and freedom by the homicide participants, this could be attributed to the belief that they might never leave the prison environment as all of them are on death row and could be executed anytime. Also, the physically poor conditions, regime that are highly controlled or unevenly applied rules particularly on homicide offenders being violent or the fact that they are not adhered to and lastly experience staff decisions as unfair heightens the feelings of not being safe within the prison environment [15].

In contrast the non-homicide offender rated freedom and safety higher because they have hope of release from the prison after their prison terms. A qualitative study which examined inmates' perceptions of prison environment in relation to jail found inmates rating prison less difficult than jail as reported by inmates' statements: Cause in prison, you know, you can play basketball, lift weight, smoke cigarettes, whatever (Respondent 3). 'Prison term will be easier, because once you get inside, you can work, there's a lot of activities; plus, you can work around (Respondent 12). 'Cause prison's just right out easier, you can lay back and you ain't gotta do nothing (Respondent 35)" [16]. The above statements suggest that prison environment may not be viewed as punitive as it is seen by public and therefore has little deterrent effect on some inmates, especially when alternatives are considered.

This adaptation in prison is influenced by the prison environment itself (i.e. are indigenous) or the prisoners preprison characteristics (i.e. are imported) [17]. According to Wright, prisoners ranked support as their highest need or concern, followed by emotional feedback, activity, structure, safety, social stimulation, freedom and privacy [3]. The findings are similar to what was reported in the current study, though safety was lower than what Wright reported. This finding could be explained by the association between adaptation in prison and aspects of confinement (type of prison and time spent in prison). The homicide offenders in the study have been in prison for a long time and are on death row. A study found that, over time, long-term prisoners increased participation in work and other prison regimes activities and reduced casual socialization [18] which might have given them a better view of the prison environment. For long-term prisoners, there are reduced feelings of hopelessness over time, and disciplinary infractions in prison declines [17]. They also immerse themselves into the daily routine of prison life, hiding their vulnerabilities and eventually losing contact with the outside world [19]. Another study on the relationship between age and prison adjustment reported that older inmates typically have more experience with incarceration. In the current study homicide offenders are on death row and older as they have spent a lot of time in the prison awaiting execution. These older, and more experienced inmates seem to have less problem coping with the prison environment than younger inmates as in the current study where homicide offenders are older than non-homicide offenders. Older inmates seem to have developed and learned systems and means for coping mentally and physically with prison throughout their incarceration experience [20]. 
DOI: $10.21522 / \mathrm{TIJMD} .2013 .07 .01 . A r t 007$

ISSN: $2520-3118$

Furthermore, research on prison subculture examined the differences in the experience of crime and criminal justice system, which may result in offenders perceiving and adapting to the prison environment differently [21]. There are arguments that prison may be preferred by some offenders, as it gives them more comfort than being on the street. Offenders may be less likely to be killed or assaulted in the prison with their serving providing them the chance to get education that are typically not affordable to some offenders on the street [22]. For offenders on short term sentences, they view the prison as a retreat from the unpredictable street, as they reported to that their imprisonment serves to provide them an opportunity to see old friends [22].

An association was found between total prison environment mean scores with age, and educational status of participants. The study found that offenders who were $\leq 25$ years of age viewed the prison environment less positively. This pattern was observed among non-homicide offenders but not among homicide offenders among which the reverse appeared to be true. Notwithstanding this, the incarceration of younger offenders in an adult prison especially a maximum-security prison has an extremely deleterious effect. This is because young prisoners could be more susceptible to negative experiences such as exploitation, than adults which may result in less satisfaction with the prison environment as observed in the current study. It is possible that the older offenders in prison might have learned to recognize and avoid potential dangers within the prison environment [20,23]. Furthermore, a study by Shover, reported that it is much easier for older and more experienced offenders to socially and psychologically adjust to the prison environment than the younger and less experienced offenders [20]. In agreement with this observation, Edwards and Potter found that a younger age group was associated with greater levels of psychological distress in prison [24].

Our study also found that those who had above primary level of education adjusted better to imprisonment. There was no difference between homicide and non-homicide offenders in this aspect. Using rates of violent incidents as a measure of prison adjustment, Finn reported that higher educational attainment was associated with better adjustment in prison [25]. Similarly, Edwards and Potter have indicated that lower educational attainment is associated with greater levels of psychological stress during imprisonment [24].

\section{Conclusion}

The study found an overall better adjustment in homicide offenders compared to their non-homicide counterparts. This observed difference was also significantly associated with certain sociodemographic variables. The study found younger employed homicide offenders with at least primary school education had better total overall score on the prison environment. There was significant association on all the subscales of the prison environment apart from safety and privacy in the homicide grope compared to their counterparts. Therefore, attention should be drawn towards socio-physical interventions among offenders based on their perceived areas of need during imprisonment.

\section{Limitation}

A few limitations in this study are worthy of mention. First, the influence of the socio-demographic variables on the prison environment was at best at association level and further studies may be required to establish causal relationship. Second, the participants' response to the assessment of prison environment may be laden with social desirability biases with a bend towards positive response so as not to be viewed as going against the prison authority. However, this is likely to be minimal in view of the anonymity involved in the data collection. 
Texila International Journal of Medicine

Volume 7, Issue 1, Apr 2019

\section{References}

[1]. Akerstrom, M. (1985). Crooks and squares (2 $2^{\text {nd }}$ ed.). New Brunswick, NJ: Transaction Publishers. [2]. Bradford, A.R. (2006). "An Examination of the Prison Environment: An Analysis of Inmate Concerns across Eight Environmental Dimensions." Electronic Theses and Dissertations. Paper 2216. http://dc.etsu.edu/etd/.

[3]. Bruce D, and Larweh E. (2017). Self-esteem, Needs satisfaction and Psychological well-being of Inmates at James Camp Prison in Ghana. International Journal of Humanities and Social Sciences and Education 4(9), 32-39.

[4]. Cai, J., and Zeng, D. (2004). Sample size/power calculation for case-cohort studies. Biometrics, 60, 1015-24.

[5]. Cobden, J., and Stewart, G. (1984). Breaking out: A perspective on long-term imprisonment and the process of release. Canadian Journal of Criminology, 26, 500-510.

[6]. Colsher, PL, Robert BW, Paul LL, Marilyn S. (1992). Health status of older male prisoners: A comprehensive survey. American Journal of Public Health 82(6):881-884.

[7]. Crank, B.R. (2010). Adapting to incarceration: Inmate perceptions of prison life and adjustment. Thesis Georgia State University. Available at: http://scholarworks.gsu.edu/cj_thesis/10 (Accessed on 12/11/2018).

[8]. Crouch, B.M. (1993). Is incarceration really worse? Analysis of offenders' preferences for prison over probation. Justice Quarterly, 10(1), 67-88.

[9]. Dhami, M.K., Ayton, P., and Loewenstein, G. (2007). Adaptation to imprisonment: Indigenous or imported? Criminal Justice and Behaviour, 34(8), 1085-110.

[10].Edwards, W.T., and Potter, R.H. (2004). Psychological distress, prisoner characteristics, and system experience in a prison population. Journal of Correctional Health Care, 10(2), 129 - 149.

[11]. Finn, M.A. (2008). Disciplinary incidents in prison: effects of race, economic status, urban residence, prior imprisonment. Journal of Offender Rehabilitation22(1/2): 143-156.

[12]. Fogel, C., and Sandra, M. (1992). The mental health of incarcerated women. Western Journal of Nursing Research 14(1):30-47.

[13]. Hurley, W., and Michael D. (1991). Psychological distress and psychiatric morbidity in women prisoners. Australian and New Zealand Journal of Psychiatry 35:461-470.

[14].Lawrence, C., and Andrews, K. (2004). Prison subculture in Poland. Crime and Delinquency, 40, 273-283.

[15].Lindquist CH. (2000). Social Integration and Mental well-being. Sociological Forum. 15:3;431-440.

[16].McGuire, J. (2000). Reducing re-offending: Putting research into practice. Presentation to a meeting of the Forensic College of the Australian Psychological Society. Adelaide, August.

[17].Ruback, R. B., Carr, T. S., and Hopper, C. H. (1986). Perceived control in prison: Its relation to reported crowding, stress, and symptoms. Journal of Applied Social Psychology, 16, 375-386.

[18].Shover, N. (1985). Aging Criminals: Beverly Hills, CA: Sage Publications.

[19].Slotboom A, Kruttschnitt C, Bijleveld K, Menting B. (2011). Psychological well-being of incarcerated women in the Netherlands: Importation or deprivation? Punishment and Society 13(2) http://doi.org/10.1177/1462474510396313.

[20].Twaddle, Andrew C. (1976). Utilization of medical services by a captive population: An analysis of sick call in a state prison. Journal of Health and Social Behaviour 17:236-248.

[21].Uzoeshi K.C. (2003). Sources of stress among Prisoners in Nigeria: Implications for Counselling. Nigerian Journal of Emotional Psychology, 5; 78-82.

[22].Williams, A., May, D.C., and Wood, P.B. (2008). The lesser evils? A qualitative study of offenders' preferences for prison compared to alternatives. Journal of Offender Rehabilitation, 46(3), 71-90.

[23]. Wooldredge, J. (1999). Inmate Experiences and Psychological well-being. Criminal Justice and Behaviour 26(2):235-250. 
DOI: $10.21522 / \mathrm{TIJMD} .2013 .07 .01 . A r t 007$

ISSN: $2520-3118$

[24].Wright, K.N. (1989). Race and economic marginality in explaining prison adjustment. Journal of Research in Crime and Delinquency, 26, 67-89.

[25].Zamble, E. (1992). Behaviour and adaptation in long-term prisoners. Criminal Justice and Behaviour, 19, 409-425.

\section{Supplementary file attached for pairwise analysis}

Pair wise comparison of Total prison environment according educational level

\begin{tabular}{|l|l|l|l|l|}
\hline Educational level & Mean & SD & t-test & P \\
\hline Informal & 0.65 & 0.16 & 0.901 & 0.370 \\
\hline Primary & 0.62 & 0.21 & & \\
\hline & & & & \\
\hline Informal & 0.65 & 0.16 & 0.860 & 0.391 \\
\hline Above primary & 0.68 & 0.18 & & \\
\hline & & & & \\
\hline Primary & 0.62 & 0.21 & 2.154 & 0.033 \\
\hline Above primary & 0.68 & 0.18 & & \\
\hline
\end{tabular}

Pair wise comparison of total prison environment according age group

\begin{tabular}{|l|l|l|l|l|}
\hline Age group & Mean & SD & t-test & P \\
\hline$\leq 25$ & 0.57 & 0.16 & 3.165 & 0.002 \\
\hline $26-40$ & 0.68 & 0.20 & & \\
\hline & & & & \\
\hline$\leq 25$ & 0.57 & 0.16 & 3.096 & 0.003 \\
\hline$>40$ & 0.68 & 0.16 & & \\
\hline & & & & \\
\hline $26-40$ & 0.68 & 0.20 & 0.009 & 0.993 \\
\hline$>40$ & 0.68 & 0.16 & & \\
\hline
\end{tabular}

Pair wise comparison of total prison environment according marital status

\begin{tabular}{|l|l|l|l|l|}
\hline Marital status & Mean & SD & t-test & P \\
\hline Never married & 0.62 & 0.16 & 2.031 & 0.044 \\
\hline Married & 0.68 & 0.20 & & \\
\hline & & & & \\
\hline Never married & 0.62 & 0.16 & 1.764 & 0.080 \\
\hline Others & 0.70 & 0.21 & & \\
\hline & & & & \\
\hline Married & 0.68 & 0.20 & 0.476 & 0.635 \\
\hline Others & 0.70 & 0.21 & & \\
\hline
\end{tabular}

